\title{
O PROGRAMA MINHA CASA \\ MINHA VIDA NA METRÓPOLE \\ PAULISTANA: ATENDIMENTO \\ HABITACIONAL \\ E PADRÕES DE SEGREGAÇÃO
}

\author{
EDUARDO MARQUES \\ LEANDRO RODRIGUES
}

\begin{abstract}
R E S U M O Este artigo analisa a produção do programa Minha Casa Minha Vida na regiāo metropolitana de São Paulo. O trabalho parte de uma revisäo das principais características e críticas ao programa para investigar o volume de produção, sua adequação à demanda habitacional para cada faixa de renda na região, assim como a localização dos empreendimentos. Utilizando técnicas de geoprocessamento, são levantados os padröes de segregaçẫo dos empreendimentos com relação a distâncias a centralidades, a equipamentos públicos e aos conjuntos produzidos pelas politicas habitacionais prévias. Os dados confirmam análises anteriores com relação à localização periférica dos empreendimentos, em especial para a primeira faixa de renda. Entretanto, considerando os padróes de localizaçâo dos conjuntos existentes e faixas de renda comparáveis, os resultados sugerem que o programa tem produzido conjuntos menos isolados do que as politicas prévias, não sendo possivel afirmar que o programa apresente os mesmos resultados territoriais que as politicas precedentes.
\end{abstract}

P A L A V R A S - C H A V E : Politica habitacional; Minha Casa Minha Vida; segregação; periferia; São Paulo.

Este artigo analisa a produção habitacional do Programa Minha Casa Minha Vida (MCMV), na Região Metropolitana de São Paulo (RMSP), em especial no que diz respeito à localização dos empreendimentos e aos padrôes de segregação presentes na metrópole. Até junho de 2013, 557 empreendimentos haviam sido contratados na RMSP, totalizando 107.589 unidades habitacionais (UH). Dentre elas, 34\% destinaram-se à faixa 1 (famílias que ganham de 0 a 3 salários mínimos), 39\% à faixa 2 (famílias que ganham 3 a 6 salários mínimos) e $27 \%$ à faixa 3 (famílias que ganham entre 6 e 10 salários mínimos).

Como se sabe, esse programa federal contribuiu sensivelmente para elevar o volume da produção habitacional nos últimos anos, após décadas de ausência de investimentos massivos do governo federal no setor, que foi bastante comemorado pela comunidade das políticas habitacionais. Entretanto, certos aspectos do programa têm sido alvos de críticas, em especial com relação ao déficit habitacional e à segregação social no espaço. Em primeiro lugar, a distribuição da produção do MCMV não estaria 
ajustada à distribuição do déficit por faixas de renda. Em nível nacional, a faixa 1 relativa a no máximo 3 salários mínimos de renda familiar mensal - representa 89,7\% do déficit (BRASIL, 2011), mas o programa incluía apenas $40 \%$ das unidades para esta faixa. Em contrapartida, as faixa de renda mais elevadas estariam recebendo muito mais recursos do que a sua participação no déficit habitacional. Um segundo conjunto de críticas diz respeito à localização geográfica dos empreendimentos. Considerando o pequeno papel destinado aos governos locais na implementaçáo do programa e a grande discricionariedade experimentada pelos produtores privados, o programa estaria gerando uma nova onda de periferização nas cidades brasileiras, com todas as conhecidas consequências negativas dessas formas de produção do espaço.

O presente artigo testa empiricamente essas hipóteses para a RMSP, analisando a distribuição da produção por faixas e as localizaçôes dos empreendimentos. Como veremos, embora o padrão de localizaçáo dos empreendimentos seja bastante periférico, as críticas presentes na literatura devem ser matizadas se levarmos em conta os padróes de segregação existentes na cidade e aqueles a que esteve submetida a produção habitacional pública produzida nas décadas passadas.

O texto tem três partes, além desta introdução e da conclusão. Na seção seguinte, explicaremos as linhas gerais do programa e as críticas que tem recebido. Na segunda seção, apresentaremos a produção na região metropolitana de São Paulo, tanto em termos quantitativos como no que diz respeito à sua distribuição geográfica geral. $\mathrm{Na}$ terceira parte, investigamos a dimensão espacial do programa em detalhes, analisando dois aspectos: os padrôes de segregação dos empreendimentos, comparando-os com as localizaçóes dos conjuntos construídos pela Companhia de Habitação de São Paulo (COHAB) e pela Companhia do Desenvolvimento Habitacional e Urbano (CDHU), bem como os conteúdos sociais e econômicos das regióes nas quais foram construídos os empreendimentos do MCMV.

\section{O MINHA CASA MINHA VIDA}

Nesta seçáo apresentamos as principais características do programa e as mais importantes críticas levantadas pelo debate. Não temos a pretensão de construir uma revisão abrangente sobre qualquer dos dois pontos, pois já se encontram disponíveis excelentes trabalhos realizando esta tarefa (CARDOSO; ARAGÃO, 2013), mas apenas construir um pano de fundo para a análise que se segue.

O programa habitacional foi constituído em 2008 e conta com duas fases: a primeira, estabelecida em 2009, por meio da Lei n $11.977 / 2009$, e a segunda em 2011, com a Lei $\mathrm{n}^{\circ}$ 12.424/2011. Além desses dois instrumentos legais, o programa é regido por uma série de portarias interministeriais e decretos presidenciais. Cada uma das duas fases do programa objetivava construir 1 milhão de moradias para famílias com renda inferior a 10 salários mínimos (SM) mensais.

Embora focado na produçáo habitacional, o programa tentava alcançar objetivos mais gerais, ligados ao reforço da atividade econômica em um contexto de crise econômica internacional (KRAUSE; LIMA NETO; BALBIM, 2013). Algumas das mais importantes decisóes em termos de desenho do programa foram derivadas do imperativo de produzir resultados imediatos, dado aquele objetivo econômico. Uma das principais consequências disso foi uma pequena aderência do MCMV às diretrizes 
estabelecidas pelo Plano Nacional de Habitação (PlanHab) de 2004, segundo críticos (BONDUKI, 2009; KRAUSE; LIMA NETO; BALBIM, 2013). A primeira fase foi concluída em 2011 com a construção de 4.493 empreendimentos totalizando 743.430 unidades (CARDOSO; ARAÚJO; JAENISCH, 2013) - e a segunda fase ainda está em andamento.

A estrutura de implementação criada para o programa foge bastante à tradição do setor habitacional no Brasil. A Caixa Econômica Federal (CEF) é gestora operacional do MCMV, recebendo e aprovando (ou não) as propostas de construção dos empreendimentos apresentadas diretamente por empresas da construção civil. Aos governos locais coube principalmente a viabilização da questão da terra, após a adesão ao programa junto à CEF.

O objetivo declarado do programa foi a redução do déficit habitacional nacional. A principal inovaçáo do programa situa-se nas condiçóes para o atendimento das famílias mais pobres, prevendo elevado subsídio para as famílias enquadradas na faixa 1 (entre 0 e 3 salários mínimos mensais de renda familiar), subsídio moderado para famílias da faixa 2 (entre 3 e 6 salários mínimos) e ausência de subsídio para as famílias da faixa 3 (entre 6 e 10 salários mínimos de renda). Além disso, as três faixas têm acesso ao Fundo Garantidor da Habitaçáo (FGHab), o qual viabiliza um sistema de compensação no caso de instabilidade de renda dos mutuários.

Cada faixa salarial possui o seu produto habitacional correspondente: famílias da faixa 1 adquirem a moradia por meio dos recursos do Fundo de Arrendamento Residencial (FAR), ou, caso estejam reunidas em uma entidade organizadora (EO), por meio do Fundo de Desenvolvimento Social (FDS). As famílias da faixa 2 e 3 têm acesso às linhas de financiamento habitacionais da CEF, que foram agrupadas ao MCMV e cujos recursos financeiros têm como origem o Fundo de Garantia por Tempo de Serviço (FGTS).

Os produtos habitacionais podem ser subdivididos também nos destinados às pessoas físicas $(\mathrm{PF})$ ou à pessoa jurídica $(\mathrm{PJ})$ : no primeiro caso os financiamentos habitacionais são contratados diretamente pelo mutuário nas agências da CEF. O segundo caso, diferentemente, envolvem operaçóes de créditos destinadas às construtoras, cujo recurso financeiro pode ser oriundo do FAR, do FDS ou do FGTS.

Adicionalmente, para os empreendimentos das faixa 2 ou 3, há ainda o financiamento feito pela CEF à pessoa física, e para a faixa 1 a participação da prefeitura que cadastra e sorteia as famílias que poderão adquirir a moradia pelo MCMV. Se o empreendimento se destina a uma entidade organizadora $(\mathrm{EO})$ da faixa 1 , não há participaçáo da prefeitura, pois é a EO quem seleciona e indica as famílias que serão beneficiadas pelo programa - na prática, as próprias famílias participantes da entidade.

Um aspecto positivo do programa é a quantidade de recursos financeiros destinados ao atendimento das famílias mais pobres, os quais são convertidos em amplo subsídio para faixa 1 e moderados subsídios para a faixa 2. Porém, o MCMV tem recebido diversas críticas, e analisaremos neste texto dois conjuntos de crítica: o atendimento da faixa 1 na RMSP e a segregaçáo socioespacial dos empreendimentos na metrópole paulistana.

Em nível nacional, o programa destinou originalmente $47 \%$ dos seus recursos financeiros para famílias enquadradas na faixa 1 (BRASIL, 2009), proporção elevada na fase 2 para $60 \%$. Porém o déficit habitacional na faixa de até 3 SM é de $89,6 \%$, segundo cálculo da Fundação João Pinheiro (BRASIL, 2011). Consequentemente, o 
déficit na faixa 1 "pode ser reduzido pelo PMCMV em 7,13\%, enquanto que na faixa de 3 a 10 SM o déficit seria reduzido em 99,63\%” (NASCIMENTO; TOSTES, 2011). Além disso, o MCMV tenderia a "[beneficiar] segmentos de classe média [...] gerando mercado para o setor privado, com risco reduzido" (BONDUKI, 2009, p. 13).

$\mathrm{Na}$ mesma direção foram Arantes e Fix (2009) ao afirmar que se manterá a tendência do não atendimento das classes que realmente precisam do subsídio. Bonduki (2009) alertou para o risco de o programa produzir moradias precárias com pequena aderência ao perfil do déficit, cuja concentração está localizada na faixa 1 . Com efeito, o autor em questão afirmou que se a meta do programa de construir 400 mil unidades habitacionais para tal faixa fosse alcançada, "apenas $6 \%$ do déficit deveria ser atendido" (BONDUKI, 2009, p. 14).

A localização dos empreendimentos é outro ponto criticado, pois o programa estabeleceu apenas um conjunto de características básicas sobre os tipos de UH e conjuntos a serem produzidos. Os primeiros estudos investigando satisfação dos beneficiários sugerem diversas críticas às tipologias e aos padróes construtivos (CARDOSO et al. 2013). Os empreendimentos estavam limitados a 500 unidades no caso de conjuntos e 300 no caso de condomínios, mas não se estabeleceu restrição à construção de empreendimentos contíguos. Como veremos a seguir na análise dos dados de São Paulo, isso aconteceu em vários casos, aumentando substancialmente a escala dos espaços construídos, mas não se pode considerar como o padrão geral do programa.

A literatura tem apontado a ausência de maiores controles sobre a localização dos empreendimentos, que levaria a mais um ciclo de produção de habitaçóes em localizaçóes periféricas, reforçando a segregação social no espaço e repetindo em certa medida as experiências do período Banco Nacional da Habitação (BNH) (ARANTES; FIX, 2009; BONDUKI, 2009; ROLNIK; NAKANO, 2009, CARDOSO; ARAÚJO; JAENISCH, 2013; PEQUENO, 2013). Em cidades com mais de 50 mil habitantes e em regióes metropolitanas, o custo da terra urbana é alto, fazendo com que as construtoras procurem terras afastadas das áreas urbanizadas de forma a diminuir seus custos e maximizar seus lucros (CARDOSO, 2013; CARDOSO; ARAÚJO; JAENISCH, 2013).

O próprio Ministério das Cidades reconheceu esse risco ao afirmar em cartilha do programa que "é importante tomar cuidado para não reproduzir as velhas práticas de programas habitacionais que constroem conjuntos com pouca qualidade e mal localizados" (BRASIL, 2010, p. 22). Por isso, o programa prioriza os estados e municípios que tenham doado "[...] terrenos localizados em área urbana consolidada para implantaçấo de empreendimentos vinculados ao programa” (BRASIL, 2010, p. 35). No entanto, esse é o único incentivo para tentar coibir a possível localização periférica dos empreendimentos e não há controles mais fortes para que esse incentivo expresso nos textos oficiais se transforme em um traço da política implementada.

Esse problema seria reforçado pelo programa ter relegado ao segundo plano a ação dos governos estaduais e municipais: "assim, os projetos não são formulados a partir do poder público ou da demanda organizada, [...] não são definidos como parte da estratégia municipal de desenvolvimento urbano e podem inclusive contrariála” (ARANTES; FIX, 2009, p. 3-4). Como os projetos são apresentados pelas construtoras, eles são "estritamente concebidos como mercadorias, rentáveis a seus proponentes” (ARANTES; FIX, 2009, p. 4). Disso decorreria a existência de uma forte lógica de mercado no programa, tal como ocorreu durante o BHN, a qual seria 
contrária ao atendimento da faixa 1.

As análises empíricas existentes confirmam essas hipóteses no que diz respeito à segregação. Araújo, Cardoso e Jaenish (2013) analisaram o padrão de distribuição dos empreendimentos na Regiáo Metropolitana do Rio de Janeiro (RMRJ), destacando a sua localizaçáa periférica. Pequeno (2013), por outro lado, realizou o mesmo exercício para a Região Metropolitana de Fortaleza (RMF), chegando a conclusóes similares com relação às tendências de periferização. Os dados reportados por Mercês (2013) e Moisés et al. (2013) também destacam o padrão periférico para o caso dos empreendimentos em Belém e Goiânia, respectivamente.

Entretanto, nos parece que a análise da segregação realizada até o momento pelos estudos existentes pode ser aprimorada. Em primeiro lugar, pois alguns estudos analisam apenas a produçáo do programa para a faixa 1, desprezando uma parte importante da produção (e também do déficit) para a faixa 2 que, em cidades específicas pode ser muito relevante e obedecer a um padrão espacial diferenciado.

Além disso, e mais importante, a análise da segregação não pode levar em conta apenas uma análise da distribuiçáo geral dos empreendimentos em mapas ou detalhando a discussão no máximo ao nível dos municípios. Embora essas dimensóes sejam importantes, representam apenas uma primeira abordagem ao problema, pois não seria razoável prever que o MCMV promoveria empreendimentos em localização muito centrais ou em bairros habitados por classes altas, como de resto não o fez nenhum programa público de habitação. Isso sugere que para analisar os padrôes de segregação, precisamos estabelecer metodologicamente parâmetros comparativos com relação a distâncias e localizaçôes. Apenas assim poderemos levar em conta as diferenças de escalas das diferentes cidades, a existência de estruturas urbanas policêntricas, assim como avaliar o programa com relação à produção habitacional pública existente. Com relação a esta última, também tem escapado ao debate que o estoque de $\mathrm{UH}$ produzido pelo Estado, por meio das Companhias Habitacionais, é mais claramente comparável com a faixa 2 do MCMV em termos de renda do que com a faixa 1, pois a produção do modelo $\mathrm{BNH}$ priorizou grupos de renda próximos àquela.

As próximas seçóes analisam o padrão espacial dos empreendimentos do MCMV na regiấo metropolitana de São Paulo levando em conta essas dimensôes. Na que se segue, analisamos as características gerais da produção do programa por faixas e no espaço da metrópole. $\mathrm{Na}$ terceira seção, testamos os argumentos críticos relativos à segregaçáo social no espaço, lançando máo de ferramentas de geoprocessamento para precisar os padróes de segregação associados aos empreendimentos para as três faixas do programa. 


\section{O MINHA CASA MINHA VIDA NA REGIÃO METROPOLITANA DE SÃO PAULO}

Até junho de 2013, foram contratados 557 empreendimentos na RMSP pelo MCMV, totalizando 107.589 unidades, sendo que naquela data 26.019 unidades já haviam sido entregues e outras 64.623 unidades estavam em obras. Dentre as unidades contratadas, $34,1 \%$ destinam-se para faixa $1,38,5 \%$ para a faixa 2 e $27,4 \%$ para a faixa 3. Apenas para estabelecer patamares de comparaçáo, vale reportar que Cardoso, Araújo e Jaenisch (2013) indicam 42.492 unidades construídas na RMRJ, 53\% delas para a faixa 1. Fortaleza, por outro lado, recebeu 15.285 unidades, sendo $80 \%$ para a faixa 1 (PEQUENO, 2013), enquanto Belém teve 7.243 unidades, sendo 49\% para a faixa 1 (MERCÊS, 2013).

Em termos de empreendimentos, a distribuição é um pouco diferente, considerando os diversos tamanhos médios dos conjuntos. A faixa 1 apresenta, na RMSP, conjuntos um pouco maiores, com 241 unidades, em média, resultando em 152 conjuntos, enquanto a faixa 2 tinha média de 176 unidades em 235 empreendimentos e a última faixa incluía 173 unidades por conjunto e 170 empreendimentos. Além disso, as unidades produzidas representavam 15,5\% do déficit de 694.047 unidades da região metropolitana de São Paulo, conforme calculado por Furtado, Lima Neto e Krause (2013). Esse cálculo de déficit segue a metodologia da FJP (BRASIL, 2011) e inclui unidades a repor por precariedade, e a prover por adensamento excessivo, comprometimento excessivo com aluguel e coabitação.

Entretanto, a distribuição da produção por faixas sugere que a proporção do déficit enfrentado efetivamente pelo programa foi bem menor, visto que o déficit se concentra fortemente na faixa 1, enquanto a produção em São Paulo se concentra nas faixas 2 e 3 . Os custos de aluguel na metrópole, por exemplo, são muito superiores à média nacional, concentrando parcelas mais elevadas do déficit em faixas de renda mais alta (a parcela do déficit por comprometimento excessivo em aluguel é de 37\% em São Paulo, contra $28 \%$ em nível nacional, utilizando os dados dos autores). Embora isso tenha sido levado em conta no Plano Nacional de Habitação, não é considerado pelo MCMV (KRAUSE; LIMA NETO; BALDIM, 2013).

Furtado, Lima Neto e Krause (2013) estimaram a participaçáo da faixa $1 \mathrm{em}$ apenas 9\% nacionalmente para 2007. A tabela a seguir estima o déficit por faixas na região metropolitana de São Paulo, partindo de dados da Fundaçâo João Pinheiro e de Furtado, Lima Neto e Krause (2013). Como se pode ver, 76\% do déficit na metrópole paulistana localiza-se na faixa $1,13 \%$ na faixa 2 e apenas $2 \%$ na faixa 3 . No conjunto, a produção do programa reduziu $15,5 \%$ do déficit, mas apenas $7 \%$ na faixa 1 e $46 \%$ na faixa 2, e além de zerar na faixa 3, a sua produção foi muito além do déficit. Portanto, embora o programa tenha contribuído para a redução do déficit na RMSP, isso ocorreu em uma proporção bem inferior ao esforço despendido pela política implementada. 
Tabela 1. Proporção do DH atendido pelo MCMV na RMSP, por faixas

\begin{tabular}{|c|c|c|c|c|}
\cline { 2 - 5 } \multicolumn{1}{c|}{} & Faixa 1 & Faixa 2 & Faixa 3 & Total \\
\hline $\begin{array}{c}\text { Déficit Habitacional Urbano } \\
\text { RMSP }\end{array}$ & 524.005 & 90.226 & 15.269 & 694.047 \\
\hline \% & 75,5 & 13 & 2,2 & 100 \\
\hline UH Produzidas na RMSP & 36.713 & 41.455 & 29.421 & 107.589 \\
\hline \% & 34,1 & 38,5 & 27,3 & 100,0 \\
\hline $\begin{array}{c}\text { Proporçáo do DH atendido } \\
\text { (em \%) }\end{array}$ & 7,0 & 45,9 & 192,7 & 15,5 \\
\hline
\end{tabular}

Fonte: Cálculo do CEM a partir de dados da CEF e da FJP e Furtando, Lima Neto e Krause (2013).

Em termos dos subcomponentes do programa, a produção na RMSP envolveu uma distribuição bastante clara. Na faixa 1 a produção do FAR foi amplamente predominante (115 empreendimentos), com FDS-Entidades em um distante segundo lugar (com 33 empreendimentos) e apenas alguns em Urbanizaçáo (e 4 empreendimentos). As faixas 2 e 3 apresentaram perfis similares, com quase apenas Apoio à produção (203 empreendimentos para a faixa 2 e 145 para a faixa 3), seguidos de Imóvel na Planta (32 empreendimentos na faixa 2 e 25 na faixa 3). De uma forma geral, portanto, quando falamos de faixa 1 estamos discutindo empreendimentos FAR alienação, assim como quando nos referimos às faixas 2 e 3 analisamos Apoio à produção.

Uma primeira abordagem à questão da segregação pode ser feita com a observação de mapas e como a distribuiçáo espacial dos empreendimentos varia substancialmente por faixas optamos por apresentar a localização de cada faixa em separado. O Mapa 1 apresenta a informação da faixa 1: o padrão é periférico, atingindo também áreas urbanas consolidadas. Merecem destaque a região de Itaquera e o extremo da Zona Leste de São Paulo, o norte da Cidade Tiradentes, mas também regióes no Jardim Ângela, no Bairro dos Pimentas em Guarulhos, em Mogi das Cruzes, em Poá e em Suzano e no ABC paulista, em especial em Diadema, Santo André e Mauá. Pode-se também observar a presença de alguns empreendimentos (três) localizados no centro de São Paulo, contratados muito recentemente e ainda não construídos. 
Mapa 1. Localização dos empreendimentos da faixa 1 do MCMV, RMSP

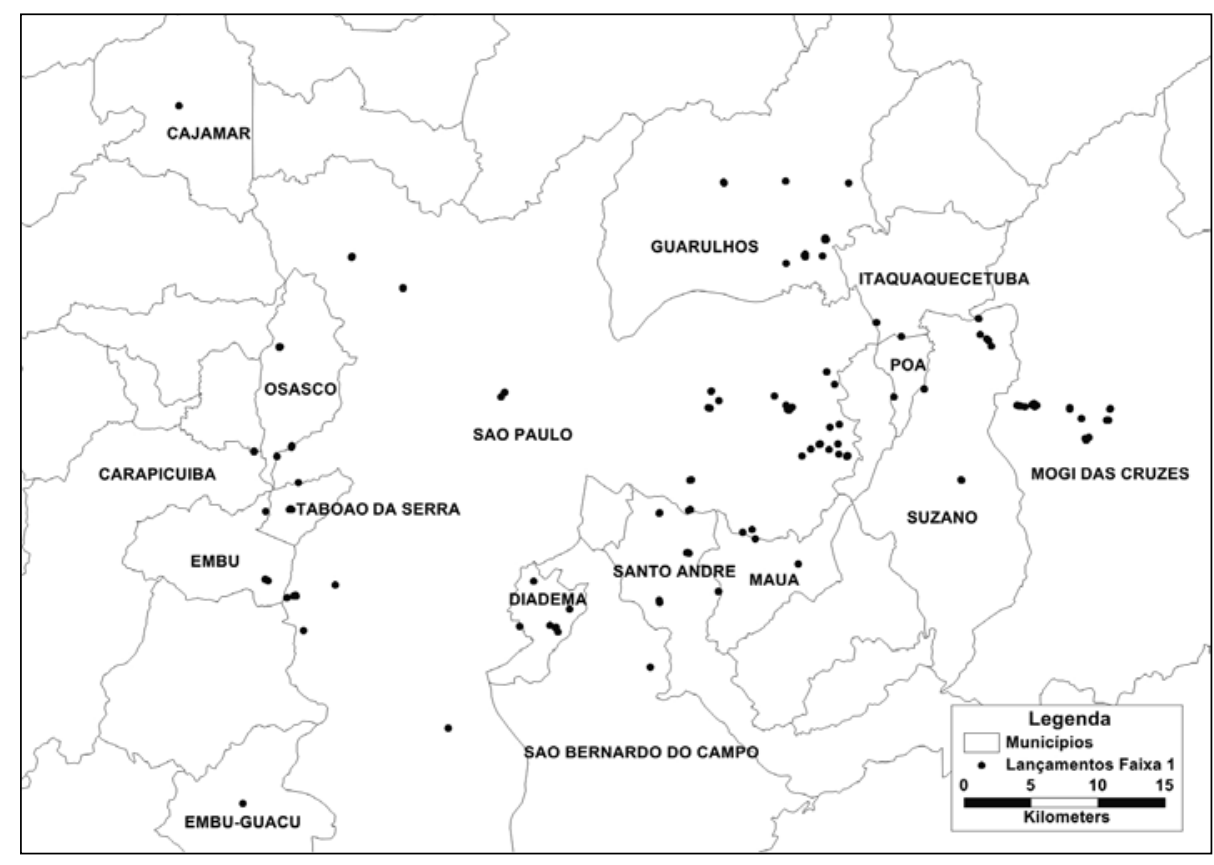

Fonte: Dados da Caixa Econômica Federal trabalhados em cartografia CEM.

O Mapa 2 apresenta a distribuição dos empreendimentos da faixa 2: o padrão da localização é mais disperso e menos periférico, com inúmeros empreendimentos na regiáo mais interna do município de Sáo Paulo, bem como no centro, no bairro Ipiranga, e na zona norte. Isso é contrastante com o que reportaram Cardoso, Araújo e Jaenisch (2013) sobre a ausência de empreendimentos nas áreas centrais do Rio de Janeiro, pois em São Paulo, existem alguns empreendimentos das faixas 2 e 3 em áreas do centro tradicional. Porém, há empreendimentos nas regiôes mais periféricas, como um grande aglomerado em Cajamar, e na região oeste, em Barueri, em Jandira, em Itapevi e em Osasco. A zona leste do município de São Paulo também recebeu muitos empreendimentos, mas em regióes mais consolidadas próximas dos centros de Itaquera e São Miguel Paulista. 
Mapa 2. Localização dos empreendimentos da faixa 2 do MCMV, RMSP

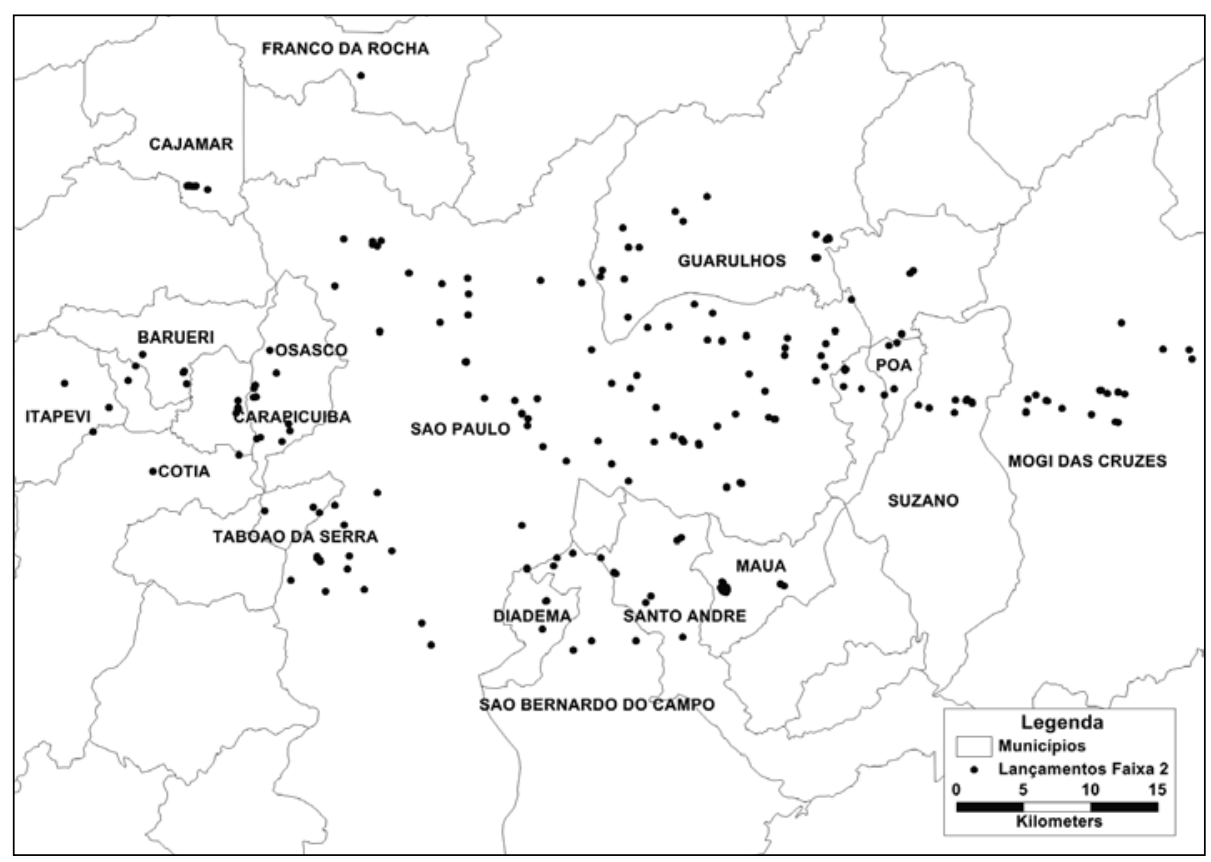

Fonte: Dados da Caixa Econômica Federal trabalhados em cartografia CEM.

O Mapa 3, por fim, apresenta a distribuição dos empreendimentos da faixa 3: o padrão é similar ao da faixa 2. Na verdade, é possível dizer que em termos de macrolocalização o conjunto dos empreendimentos da faixa 3 é mais periférico do que o da faixa 2 ao menos no que diz respeito à presença de conjuntos na região mais interna da metrópole. Chama atenção também uma menor presença de conjuntos em Mogi das Cruzes. O Mapa indica uma distribuição ampla na zona Leste de São Paulo e no Jardim Ângela, nos municípios do oeste da metrópole e em Guarulhos e na região do $\mathrm{ABC}$ paulista, e no município de Sáo Paulo próximo ao ABC.

Vale ressaltar a presença de agrupamentos de empreendimentos em Cajamar, em Mauá, e no bairro de Campo Limpo, em São Paulo. Na verdade, trata-se de agrupamentos de empreendimentos para as faixas 2 e 3 construídos por várias construtoras diferentes incluindo 19 empreendimentos no sul de Cajamar e 30 empreendimentos em Mauá. Além disso, há alguns empreendimentos que são para faixa 2 e 3 ao mesmo tempo, como é o caso do Máximo Guarulhos, da construtora Cury, localizado na Vila Augusta. Por fim, devemos mencionar que alguns empreendimentos possuem parte das UH vendidas pelo MCMV, e o restante é comercializado fora do MCMV, para famílias que ganham mais do que 10 SM: é o caso do AcquaPark Condomínio Club, localizado também na cidade de Guarulhos.

Esses fenômenos merecem maior atenção das futuras pesquisas sobre o MCMV: é preciso investigar quais são as áreas das metrópoles que tendem a concentrar empreendimentos para faixa 2 e 3, bem como quais são as estratégias envolvidas na divisão das $\mathrm{UH}$, do mesmo empreendimentos que serão vendidas para faixa 2 e 3 , assim como daquelas que não serão comercializadas pelo MCMV. 
Mapa 3. Localização dos empreendimentos da faixa 3 do MCMV, RMSP

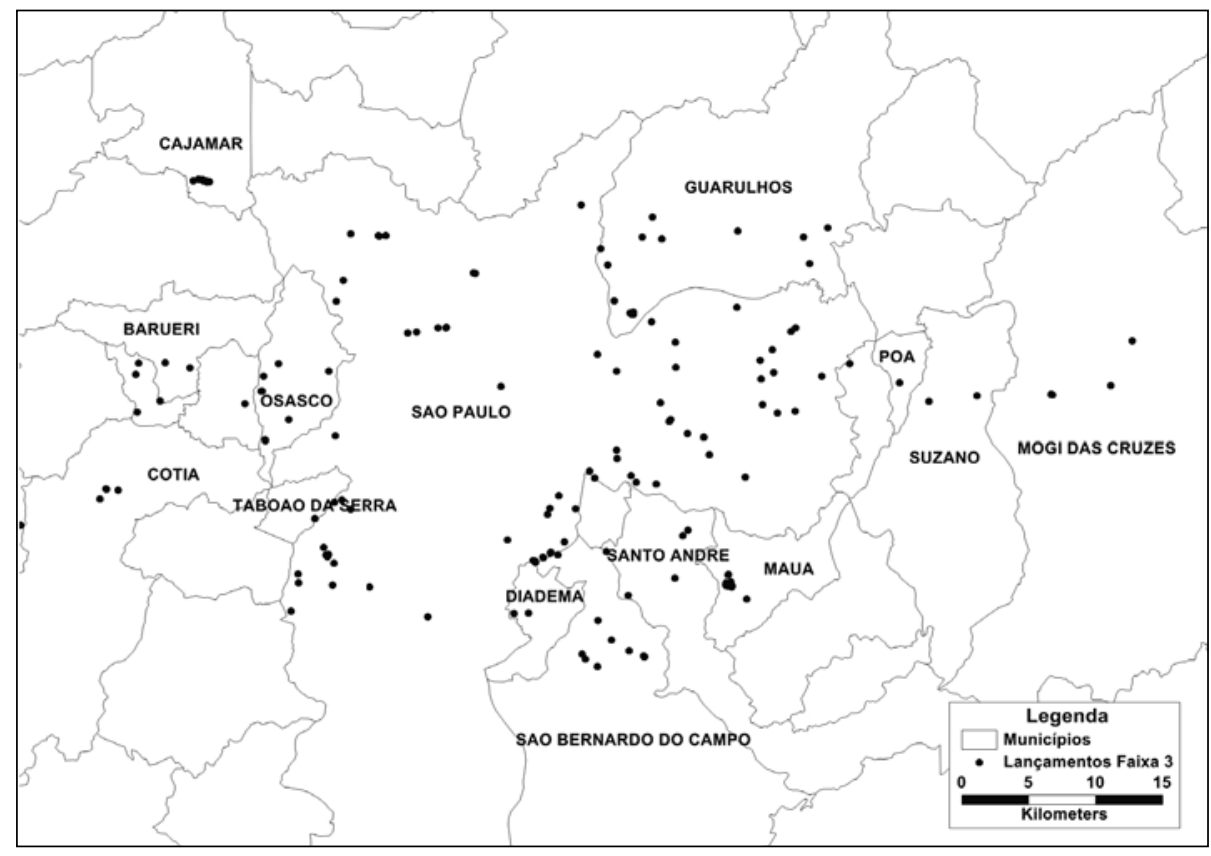

Fonte: Dados da Caixa Econômica Federal trabalhados em cartografia CEM.

\section{ANALISANDO SEGREGAÇÃO RESIDENCIAL NO MINHA CASA MINHA VIDA}

A análise dos padrões de segregação nos conjuntos do MCMV será realizada em várias etapas de detalhamento sucessivo de forma a investigarmos não apenas a segregação em termos geométricos, mas socioespaciais, sempre considerando as faixas do programa de forma diferenciada. Primeiramente, avaliamos a escala dos conjuntos. Em segundo lugar, investigamos a distância dos empreendimentos a centralidades na regiāo metropolitana. Em seguida, investigamos a distância dos empreendimentos a equipamentos importantes, como as redes do metrô e da CPTM, assim como de conjuntos já construídos pela $\mathrm{COHAB}$ e pelo CDHU. Em um terceiro momento, comparamos os conteúdos sociais dos entornos dos empreendimentos para avaliar se a construção dos conjuntos inserirá seus moradores em entornos menos pobres ou mais pobres e precários em termos urbanos.

Com relaçáo à escala dos conjuntos, dentre os empreendimentos contratados, apenas 16 tinham mais de 500 unidades, limite de tamanho do programa, sendo que dois deles tinham 1.500 unidades cada. Entretanto, a mera observação dos números de empreendimentos não expressava a concentração espacial dos empreendimentos. Sáo inúmeros os agrupamentos de empreendimentos em locais contíguos, embora por vezes produzidos por empresas distintas. No total, 38 agrupamentos apresentam mais de 500 unidades, sendo o maior deles em Cajamar para as faixas 2 e 3, totalizando aproximadamente 3.200 unidades. Portanto, embora haja conjuntos de porte, a maior parte dos empreendimentos não apresenta grande escala.

Para a análise das distâncias das centralidades, consideramos não apenas as 
distâncias às principais centralidades da metrópole, mas também a subcentros regionais, pois embora a distribuição dos empregos seja fortemente radial e concêntrica a partir do Centro Expandido diversos outros serviços se encontram disseminados por várias centralidades. Foram consideradas, portanto, não apenas as distâncias às centralidades mais importantes - Praça da Sé (centro histórico) e Berrini-Marginal Pinheiros (atual centro de negócios), mas também à centralidade mais próxima considerando uma estrutura policêntrica composta de: Praça da Sé, Berrini-Faria Lima e os centros de Santo Amaro, da Penha, de São Bernardo do Campo, de Santo André, de Osasco, de Mogi das Cruzes e de Guarulhos. Vale dizer que as distâncias reportadas dizem respeito a distâncias euclidianas simples entre a localização pontual do empreendimento e a centralidade mais próxima. A informação é apresentada na tabela a seguir. Como é difícil analisarmos as distâncias sem um padrão externo de comparação, calculamos e incluímos também na tabela as distâncias de conjuntos da $\mathrm{COHAB}$ e do CDHU às mesmas centralidades.

Tabela 2. Distâncias a centralidades por faixas MCMV, COHAB e CDHU (km)

\begin{tabular}{|c|c|c|c|c|c|c|c|c|c|c|}
\cline { 2 - 11 } \multicolumn{1}{c|}{} & \multicolumn{2}{c|}{ Faixa 1 } & \multicolumn{2}{c|}{ Faixa 2 } & \multicolumn{2}{c|}{ Faixa 3 } & \multicolumn{2}{c|}{ COHAB } & \multicolumn{2}{c|}{ CCHU } \\
\cline { 2 - 10 } \multicolumn{1}{c|}{} & Média & Desvio & Média & Desvio & Média & Desvio & Média & Desvio & Média & Desvio \\
\hline Distância a Sé & 26,0 & 12,0 & 21,3 & 10,5 & 18,7 & 7,6 & 18,4 & 6 & 23,3 & 10,2 \\
\hline $\begin{array}{c}\text { Distância a } \\
\text { Berrini }\end{array}$ & 28,2 & 14,3 & 23,3 & 11,9 & 19,5 & 8,3 & 22,2 & 8,2 & 25,8 & 14,2 \\
\hline $\begin{array}{c}\text { Distância à } \\
\text { centralidade } \\
\text { mais próxima }\end{array}$ & 9,5 & 4,9 & 7,8 & 4,8 & 7,7 & 4,5 & 10,5 & 4,3 & 10,2 & 6,5 \\
\hline
\end{tabular}

Fonte: Dados da Caixa Econômica Federal, trabalhados sobre cartografias CEM.

Observemos primeiro os empreendimentos do MCMV. Como se pode ver, a distância varia entre as faixas, mas tende a ser relativamente estável no interior delas, como atestam os baixos desvios em relação às médias. Os padróes de distância são claramente ordenados, sendo a faixa 1 mais distante e a faixa 3 a mais próxima às centralidades analisadas. A tabela nos indica grandes distâncias médias entre os empreendimentos e as centralidades mais importantes da regiáo metropolitana (Sé e Berrini) - entre aproximadamente 19 e 28 quilômetros. Entretanto, quando consideramos centralidades secundárias no interior da metrópole, as distâncias caem substancialmente para entre 8 e 10 quilômetros. Outra informação interessante é que a diferença entre as distâncias das faixas do programa caem quando consideramos centralidades secundárias, embora a primeira faixa continue a apresentar as maiores distâncias. Apesar dessas ponderaçôes, as distâncias dos empreendimentos do Minha Casa a centralidades são significativas, mesmo com relação às centralidades secundárias, permitindo sustentar uma razoável segregação desses empreendimentos na escala da metrópole.

As informações relativas a conjuntos da $\mathrm{COHAB}$ e do CDHU, entretanto, estabelecem um padrão externo de comparação que acrescenta informaçóes interessantes. As distâncias médias dos conjuntos existentes na região metropolitana de São Paulo variam entre 18 a 26 quilômetros das centralidades mais importantes e aproximadamente 10 quilômetros de qualquer centralidade, valores bastante 
próximos dos encontrados nos empreendimentos do Minha Casa Minha Vida, em especial dos empreendimentos da faixa 1. Empreendimentos da faixa 3 do MCMV, por outro lado, têm padrôes de distâncias similares aos conjuntos da COHAB com relação à Sé e à Berrini, mas apresentam distâncias substancialmente menores (em torno de 8 quilômetros) do que esses (em torno de 10 quilômetros) no que diz respeito às demais centralidades.

Portanto, em termos de distância a centralidades, os empreendimentos da faixa 1 do MCMV se assemelham bastante a conjuntos da COHAB e sobretudo do CDHU. Os empreendimentos das faixas 2 e 3 apresentam menores distâncias do que os conjuntos já existentes na metrópole paulistana. Vale ressaltar que a faixa de renda de atendimento tradicional da $\mathrm{COHAB}$ e do $\mathrm{CDHU}$ não coincidia com a faixa 1 , mas com a faixa 2. Portanto, é com essa faixa que se pode comparar efetivamente as políticas do modelo $\mathrm{BNH}$ e, consequentemente, ao menos sob esse ponto de vista, a localização da produção do MCMV é menos periférica que as políticas anteriores.

Entretanto, é muito diferente estar próximo ou distante a uma centralidade principal ou secundária. Por essa razão, a Tabela abaixo explora as diferentes centralidades presentes no universo de cada faixa. Como se pode ver, as centralidades mais comuns para as três faixas são Osasco, Santo André, Mogi das Cruzes, Guarulhos e Penha, embora com predominância diferente dependendo da faixa. Enquanto para a faixa 1 Mogi e Penha se destaquem, para a faixa 2 o destaque está em Osasco, Penha e Mogi e para a faixa 3 em Osasco e Santo André. Vale destacar que nesse caso as médias dizem respeito a empreendimentos e não a unidades.

Tabela 3. Distribuição dos centros mais próximos a empreendimentos MCMV, por faixas $(\%)$

1 As maiores distâncias ocorrem entre seis conjuntos localizados no município de Guararema e conjuntos da COHAB e do CHDU (40 e 11 quilômetros, respectivamente), além das estações do Metrô (45 quilômetros). A maior distância dentre todas as analisadas é de 13 quilômetros, entre estações da CPTM e esses mesmos empreendimentos. Esses resultados são de alguma forma esperados, já que a rede do metrô só alcança o município de São Paulo e a COHAB é uma empresa pública do município de São Paulo.

\begin{tabular}{|l|c|c|c|}
\cline { 2 - 4 } \multicolumn{1}{c|}{} & Faixa 1 & Faixa 2 & Faixa 3 \\
\hline Mogi das Cruzes & 26 & 16,2 & 4,1 \\
\hline Penha & 20,1 & 17,4 & 15,9 \\
\hline Osasco & 13 & 20,4 & 23,5 \\
\hline Santo André & 12,3 & 14,5 & 20,6 \\
\hline Guarulhos & 10,4 & 10,2 & 11,2 \\
\hline Santo Amaro & 11 & 7,7 & 10 \\
\hline Sáo Bernardo & 5,2 & 4,3 & 10,6 \\
\hline Sé & 1,9 & 8,5 & 4,1 \\
\hline Berrini & 0 & 0,9 & 0 \\
\hline & 100,0 & 100,0 & 100,0 \\
\hline
\end{tabular}

Fonte: Dados da Caixa Econômica Federal, trabalhados sobre cartografias CEM.

Mas qual será o padrão de acessibilidade dos empreendimentos a equipamentos? Além disso, como usamos os conjuntos existentes da COHAB e do CDHU como parâmetro? Será que esses se localizam próximos aos empreendimentos do Minha Casa? Parar testar essas dimensôes, calculamos as distâncias euclidianas simples dos empreendimentos do Minha Casa Minha Vida, a estações do Metrô e da CPTM, à escola mais próxima e aos conjuntos existentes. A informaçáo é apresentada na tabela a seguir. Considerando a existência de algumas poucas localizações que fogem ao padrão, reportamos as medianas, que descrevem mais precisamente os padrões gerais. ${ }^{1}$ 
Tabela 4. Distâncias medianas a conjuntos e equipamentos $(\mathrm{km})$, por faixa

\begin{tabular}{|l|c|c|c|c|c|c|}
\cline { 2 - 7 } \multicolumn{1}{c|}{} & Est. Metro & Est. CPTM & $\begin{array}{c}\text { Hospital } \\
\text { SUS }\end{array}$ & Escola & COHAB & CDHU \\
\hline Faixa 1 & 4,0 & 3,6 & 4,7 & 0,3 & 3,5 & 1,9 \\
\hline Faixa 2 & 4,1 & 2,5 & 4,8 & 0,3 & 4,6 & 2,6 \\
\hline Faixa 3 & 4,6 & 3,4 & 3,7 & 0,3 & 3,9 & 2,5 \\
\hline COHAB & 2,3 & 3,4 & 1,5 & 0,1 & & \\
\hline Cdhu & 3,9 & 2,9 & 2,8 & 0,2 & & \\
\hline
\end{tabular}

Fonte: Dados da Caixa Econômica Federal, trabalhados sobre cartografias CEM.

As distâncias às estaçôes da CPTM são mais baixas do que a estaçôes do metrô para todas as faixas, o que é esperado, considerando o padrão mais periférico da primeira rede. A diferença é superior para empreendimentos das faixas 2 e 3 . As distâncias dos conjuntos existentes da COHAB e do CDHU, por outro lado, tendem a ser bem inferiores a estaçóes de metrô, produto da concentração de conjuntos em Itaquera, mas similar aos dos empreendimentos do Minha Casa no que diz respeito à CPTM.

A presença de equipamentos escolares é bastante próxima para todas as faixas, o que já era de se esperar considerando a distribuição ampla desses equipamentos no território nos dias de hoje, mesmo nas periferias mais distantes. Por outro lado, a distância a hospitais públicos é substancialmente maior para os empreendimentos do Minha Casa, em especial nas faixas 1 e 2, do que dos conjuntos existentes. A pequena distância dos conjuntos da $\mathrm{COHAB}$ é produto da grande concentração desses na Cidade Tiradentes.

Considerando o desenho do programa, seria de se esperar que empreendimentos da faixa 1 fossem os mais próximos aos conjuntos existentes, que os da faixa 3 fossem os mais distantes, e que as maiores distâncias ao sistema de transportes fossem observadas com os conjuntos da faixa 1 (e as menores com os da faixa 3). Náo é exatamente o quadro que se observa na tabela. Embora empreendimentos da faixa 1 tendam a estar mais próximos de conjuntos, os da faixa 3 não são os mais distantes. Por outro lado, os empreendimentos da faixa 3 são os mais distantes do metrô, que tem uma rede menos periférica do que a CPTM. Além disso, os empreendimentos do MCMV apresentam maior proximidade com conjuntos do $\mathrm{CDHU}$ do que da $\mathrm{COHAB}$ em todas as faixas.

Segregação residencial diz respeito à homogeneidade de conteúdos sociais das áreas da cidade, separados por distâncias de outros espaços também homogêneos. Desse modo, outra forma de acessarmos as dimensôes relativas à segregação é comparando as características dos entornos dos empreendimentos com as que podemos imaginar que sejam os dos futuros moradores dos empreendimentos. As ferramentas de geoprocessamento nos auxiliam nisso mais uma vez, pois podemos gerar estimativas a partir dos dados do Censo de 2010 das características sociais dos moradores dos entornos dos empreendimentos a uma dada distância. No caso, utilizamos entorno de 500 metros. A tabela a seguir apresenta a informação, incluindo dados similares relativos a conjuntos da COHAB e do CDHU e para o conjunto da regiáo metropolitana, para estabelecer parâmetros de comparação. 
Tabela 5. Características sociais médias dos entornos (500 metros) do MCMV, COHAB, CCHU e RMSP, 2010

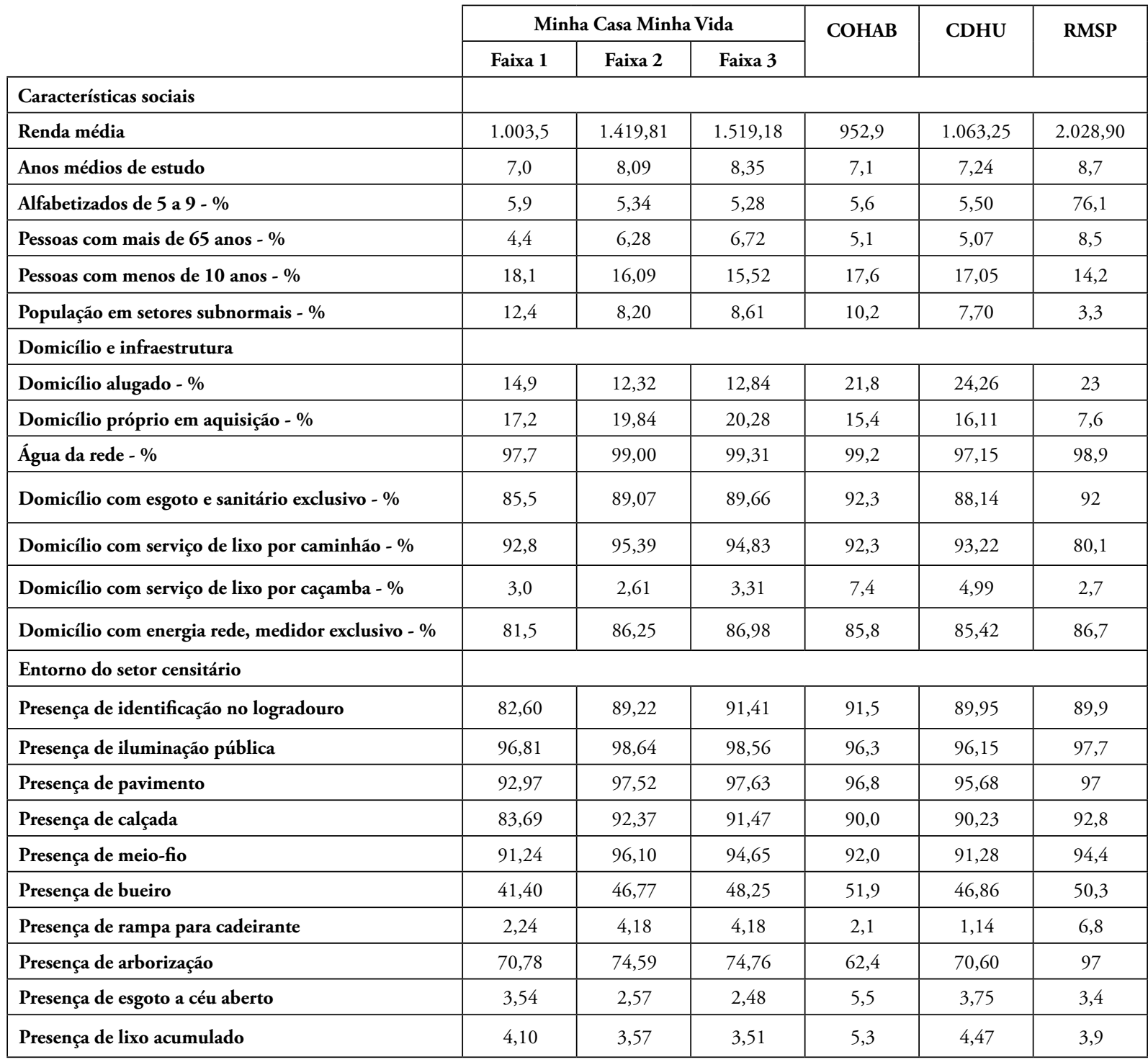

Fonte: Dados da Caixa Econômica Federal, trabalhados sobre cartografias CEM.

Como se pode ver, em termos de características sociais, o entorno dos empreendimentos da faixa 1 distancia-se muito das médias da região metropolitana e se assemelha às dos conjuntos do CDHU e, em especial, da COHAB. Na verdade, a semelhança com o entorno de conjuntos existentes é impressionante, sugerindo espaços praticamente iguais. $\mathrm{O}$ único indicador que sugere maior precariedade nos locais de implantaçáo dos empreendimentos da faixa 1 é a proporção da população habitante de setores subnormais. Os entornos das faixas 2 e 3, como era de se esperar, apresentam renda, escolaridade e alfabetização mais altas e estrutura etária mais velha, embora ainda distantes das médias da metrópole.

Com relação às características dos domicílios e ao acesso a infraestrutura, as condiçôes das faixas 2 e 3 também são melhores, quando comparadas com a faixa 1 e quase indiferenciadas entre si. A presença relativa de domicílios alugados é maior no entorno dos empreendimentos do Minha Casa, assim como é menor a proporção de 
domicílios próprios em aquisição, provavelmente como produto da maior escala dos conjuntos mais antigos, aglomerados em complexos. Novamente as condições são inferiores à média da metrópole, mas chama a atenção que os entornos de condomínios da COHAB e do CDHU tendam a ter maiores proporçôes de lixo coletado por caçamba e menos medidores coletivos de energia, indicadores de baixa qualidade do serviço de infraestrutura prestado.

A maior escala dos conjuntos pode explicar também os indicadores de entorno, apresentados na parte inferior da tabela. Essas variáveis dizem respeito a elementos do espaço construído observados pelo recenseador do Censo durante a coleta de dados, e não ao domicílio em si. Como se pode ver, os empreendimentos do programa Minha Casa Minha Vida apresentam condiçôes muito inferiores às médias da cidade, embora as condiçóes novamente melhorem entre as faixas da mesma forma que anteriormente. Nesse caso, entretanto, é a faixa 2 que se assemelha aos conjuntos existentes da COHAB e do CDHU, com os empreendimentos da faixa 3 apresentando melhores condiçôes médias. Os empreendimentos da faixa 1, por outro lado, foram implantados em locais caracterizados mais frequentemente por um grau de precariedade urbana mais alta em termos da ausência de meios fios, bueiros, rampas para cadeirantes, pavimentação etc. Exceto por alguns indicadores específicos, entretanto, os patamares de infraestrutura não são muito baixos, apesar de serem inferiores aos das demais faixas e conjuntos existentes.

Portanto, em termos de entorno, os empreendimentos da faixa 1 se assemelham aos conjuntos habitacionais existentes na metrópole, enquanto os das faixas 2 e 3 apresentam melhores condiçóes, exceto para o entorno dos setores, onde apenas a faixa 3 apresenta melhores condiçóes. Como a produçáo tradicional das companhias habitacionais estava concentrada em faixas similares à faixa 2, é possível dizer que a semelhança com os entornos das COHAB contribui, embora de forma tênue, para a redução da segregação, diferentemente do que tem sido considerado pela maior parte dos analistas.

Por fim, para completarmos a análise dos empreendimentos sob o ponto de vista da segregação, cruzamos a sua localização com uma tipologia de espaços construída em Marques (2013) com dados do Censo de 2010. Essa classificação foi obtida a partir de análise de cluster das presenças relativas de classes sociais, construídas seguindo a classificação ocupacional EGP (ERICKSON; GOLDENTHORPE; PORTOCARRERO, 1979), alterada por Barbosa e Marschner (2013). Com tais procedimentos metodológicos, foram delimitados cinco tipos de espaço relativamente homogêneos em termos de seus conteúdos sociais (mas descontínuos no território da metrópole). Enquanto na análise precedente analisamos as características dos moradores no espaço imediato de inserçáo dos empreendimentos, nesse caso a comparação é entre aquelas características sociais e os conteúdos dos sociais dos espaços em que se inserem em uma escala mais ampla. A informação é apresentada no gráfico, mostrando a predominância de cada tipo de espaço na produção de cada faixa. 
Gráfico 1. Distribuiçáo dos empreendimentos de cada faixa por tipo de espaço

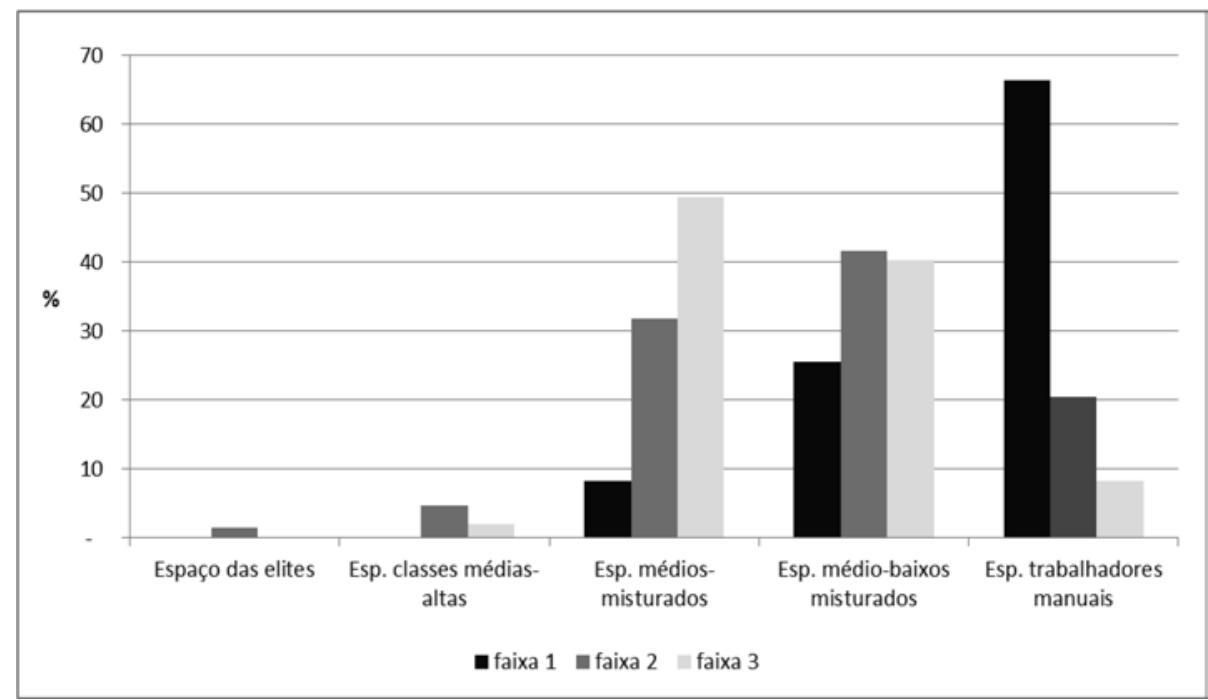

Fonte: Dados da Caixa Econômica Federal, trabalhados sobre cartografias CEM.

Como era de se esperar, a localização das faixas varia substancialmente por tipo de espaço, embora obedeça a um claro ordenamento. A faixa 1 está fortemente concentrada em espaços dos trabalhadores manuais - 66\%, embora com uma parcela não desprezível em espaços médio-baixos misturados - 26\%. As faixas 2 e 3 apresentam perfis relativamente similares. Em ambos os casos a predominância é em espaços médiosmisturados e médio-baixos misturados, embora com ênfases invertidas. A faixa 3 apresenta maior proporção de sua produção em espaços médios-misturados, enquanto a faixa 2 tem mais presença em espaços médio-baixos misturados. A faixa 2, por outro lado, também apresenta uma parcela não desprezível em espaços dos trabalhadores manuais (cerca de 20\%). Não há praticamente nenhum empreendimento em espaços das elites e muitos poucos da faixa 2, principalmente, no espaço das classes médiasaltas misturadas. Essas informaçóes confirmam as anteriores e reforçam a similaridade em termos de localização da faixa 1 com a produção habitacional pública tradicional paulistana (e brasileira), assim como indicam que as faixas 2 e 3 tenderam a produzir um padrão diferente e muito menos periférico em termos socioespaciais.

\section{CONCLUSÃO}

Como vimos, o programa Minha Casa Minha Vida apresentou uma expressiva produção desde o seu início na regiáo metropolitana de São Paulo, alcançando cerca de 105.000 unidades. Diferentemente de outras regiōes do país, o programa atendeu uma parcela relativamente pequena da faixa 1 e mais altas proporçóes das faixas de maior renda. A proporção de atendimento à faixa 1 foi relativamente reduzida - em torno de $35 \%$ (essa proporção alcançou $60 \%$ na média nacional), o que representou uma baixa proporção do déficit nessa faixa atendido - cerca de $7 \%$. Por outro lado, $46 \%$ do déficit estimado para a faixa 2 foi atendido, enquanto o déficit da faixa 3 foi atendido integralmente e ultrapassado amplamente.

Em termos de localização, ficou comprovado para São Paulo o padrão periférico 
de localizaçáo dos empreendimentos já destacado pela literatura. Os empreendimentos do programa se localizam relativamente longe de centralidades e de grandes equipamentos de transporte, mas não de forma discrepante com relação ao que tradicionalmente o poder público produz na região. Em geral, os empreendimentos da faixa 1 tendem a ter distâncias a centralidades relativamente similares aos de conjuntos existentes da $\mathrm{COHAB}$ e do $\mathrm{CDHU}$, enquanto empreendimentos das faixas 2 e 3 apresentam acessibilidade maior a centralidades. Em termos dos conteúdos sociais dos entornos, os entornos dos empreendimentos da faixa 1 novamente se assemelham muito aos de conjuntos existentes, enquanto os das faixas 2 e 3 se distanciam desse e se aproximam das médias da metrópole. Essa informação é confirmada pela análise do tipo de espaço onde os conjuntos têm sido implantados. Enquanto empreendimentos da faixa 1 são predominantemente implantados em espaços de trabalhadores manuais, mantendo o padrão de segregaçáo, empreendimentos das faixas 3 e 2 têm sido lançados principalmente nos espaços médios misturados e médios-baixos misturados, respectivamente. Como os conjuntos existentes beneficiaram principalmente uma faixa correspondente à faixa 2 do MCMV, é possível dizer que o padrão de localizaçóes na região metropolitana de São Paulo é menos periférica do que a produção anterior, embora as distâncias sejam bastante elevadas.

Em termos de segregação residencial, portanto, é possível dizer que os empreendimentos do programa na região metropolitana de São Paulo têm seguido a lógica geral dos padróes de segregação da metrópole, mas sem intensificá-los, como sugeriria uma parte substancial da literatura existente. Dado o porte da produção executada, entretanto, é também evidente que se perdeu uma importante chance de contribuir para uma alteração mais intensa dos padróes de segregaçáo social presentes na metrópole paulistana.

\section{REFERÊNCIAS BIBLIOGRÁFICAS}

ARANTES, P.; FIX, M. Como o governo Lula pretende resolver o problema da habitação (Parte 1, 2 e 3). Website. Disponível em: <http://passapalavra.info/?p=9445>. Acesso em: 9 mai. 2009. ARAÚJO, F. S.; CARDOSO, A. L.; JAENISCH, S. T. Morando No Limite: Sobre Padróes De Localização E Acessibilidade Do Programa Minha Casa Minha Vida Na Região Metropolitana Do Rio De Janeiro. XV Encontro da Associação Nacional de Pós-Graduação e Pesquisa em Planejamento Urbano e Regional, 2013.

BALBIM, R. N.; KRAUSE, L. H.; NETO, V. C. L. Minha Casa, Minha Vida, Nosso crescimento: como fica a política habitacional? XV Encontro da Associação Nacional de Pós-Graduação e Pesquisa em Planejamento Urbano e Regional, 2013.

BARBOSA, R.; MARSCHNER, M. Uma proposta de padronização de classificaçóes em pesquisas do IBGE (Censos 1960-2010) e PNADs (1981-2011): educação, setores de atividade econômica e ocupação (ISCO-88, EGP11 e ISEI). Working paper. São Paulo: CEM, Mimeo, 2013.

BONDUKI, N. Do Projeto Moradia ao Programa Minha Casa Minha Vida. Teoria e Debate, v. 82 , p. 8-14, maio/jun. 2009.

BRASIL. Ministério das Cidades. Secretaria Nacional de Habitação. Avanços e Desafios: Política Nacional de Habitação. Brasília, DF: Ministério das Cidades, 2009.

BRASIL, Ministério das Cidades. Secretaria Nacional de Habitação. Como produzir moradia bem localizada com recursos do programa minha casa minha vida? Brasília, DF: Ministério das Cidades, 2010.

\begin{abstract}
Eduardo Marques é professor livre-docente do Departamento de Ciência Política da USP e pesquisador do Centro de Estudos da Metrópole. Doutor em Ciências Sociais (Unicamp). E-mail: <ecmarq@uol.com.br>.
\end{abstract}

Leandro Rodrigues é pesquisador do Centro de Estudos da Metrópole, graduado em ciências sociais (FFLCH/USP). Mestrando do Departamento de Ciência Política da USP. E-mail: <leandro.padua.rodrigues@usp.br>. 
BRASIL, Ministério das Cidades. Déficit Habitacional no Brasil 2008. Brasília, DF: Secretaria Nacional de Habitação, 2011. 140p,

CARDOSO, A.; ARAGÃO, T. Do fim do BNH ao Programa Minha Casa Minha Vida: 25 anos da política habitacional no Brasil. In: CARDOSO, A. (Org.). O programa Minha Casa Minha Vida e seus efeitos territoriais. Rio de Janeiro: IPPUR/Letra Capital, 2013.

CARDOSO, A. (Org.). O Programa Minha Casa Minha Vida e seus efeitos territoriais. Rio de Janeiro: Letra Capital, 2013. 322p.

CARDOSO, A. et al. Minha Casa Minha Sina: implicações da recente produção habitacional pelo setor privado na Zona Oeste da cidade do Rio de Janeiro. In: CARDOSO, A. (Org.). O programa Minha Casa Minha Vida e seus efeitos territoriais. Rio de Janeiro: IPPUR/Letra Capital, 2013.

DIAS, E. Do Plano Real ao Programa Minha Casa, Minha Vida: negócios, votos e as reformas da habitação. São Paulo: USP/DCP, dissertaçáo de mestrado, 2012.

ERIKSON, R.; GOLDTHORPE, J.; PORTOCARRERO, L. Intergenerational Class Mobility in Three Western European Societies. British Journal of Sociology, 30, p. 415-441, 1979.

LIMA, J. et al. A promoçáo habitacional através do Programa Minha Casa Minha Vida na Regiāo Metropolitana de Belém. In: CARDOSO, A. (Org.). O programa Minha Casa Minha Vida e seus efeitos territoriais. Rio de Janeiro: IPPUR/Letra Capital, 2013.

MARQUES, E. Os espaços da metrópole. In: MARQUES, E. (Org.). São Paulo no século XXI: permanências, transformaçôes e desigualdades na metrópole. São Paulo: CEM, mimeo, 2013. MERCÊS, S. Programa Minha Casa, Minha Vida na Região Metropolitana de Belém: localização dos empreendimentos e seus determinantes. . In: Cardoso, A. (org.). O programa Minha Casa Minha Vida e seus efeitos territoriais. Rio de Janeiro: IPPUR/Letra Capital, 2013. MINHA CASA, Minha Vida. WebSite. Disponível em: <http://www.sinduscon-rio.com.br/ mcmv/CARTILHADACAIXA.pdf $>$. Acesso em: 31 ago. 2009.

MOYSÉS, A. et al. Impactos da produção habitacional contemporânea na Regiáo Metropolitana de Goiânia: dinâmica, estratégias de mercado e a configuração de novas espacialidades e centralidades. In: CARDOSO, A. (Org.). O programa Minha Casa Minha Vida e seus efeitos territoriais. Rio de Janeiro: IPPUR/Letra Capital, 2013.

NASCIMENTO, D.; TOSTES, S. Programa Minha Casa Minha Vida: a (mesma) política habitacional no Brasil. Arquitextos, São Paulo. WebSite. Disponível em: <http://www.vitruvius. com.br/revistas/read/arquitextos/12.133/3936>. Acesso em: 02 set. 2011.

PEQUENO, L. Minha Casa, Minha Vida em Fortaleza: novas periferias? XV Encontro da Associação Nacional de Pós-Graduação e Pesquisa em Planejamento Urbano e Regional, 2013. ROLNIK, R. La Democracia en el filo de la navaja: límites y posibilidades para la implementación de una agenda de reforma urbana en Brasil. Revista Eure, v. xxxv, n. 104, p. 5-27, 2009.

ROLNIK, R.; NAKANO, A. As armadilhas do pacote habitacional. Le Monde Diplomatique, São Paulo, n. 2 p. 4-5, 2009.

A B S T R A C T This article analyzes the production of the Minha Casa Minha Vida program at the metropolitan region of São Paulo. Departing from a review of the main features of the program and the criticisms that have been raised against it, the study investigates its production, its adequacy to the housing demand for each income band at the region, as well as the location of the projects. Using GIS techniques, we study the segregation patterns of the projects considering their distances to centralities, to public equipment and to the housing projects produced by previous policies. The data confirm previous analyses which state the peripheral location of the projects, in special for the first income band. However, considering the location of the existing projects for comparable income bands, 
E D U A R O M A R Q E S L E A N D R R O D R I G E S

the results suggest that the program produced less isolated projects than previous policies, not being accurate to state that the program presents the same territorial results than the preceding policies.

K E Y W O R D S : Housing policy; Minha Casa Minha Vida; residential segregation; urban periphery; São Paulo. 